\title{
A CIDADE (DES)ORDENADA E O COTIDIANO
}

\author{
Amélia Luisa Damiani
}

À época da dissertação de mestrado, ao me reportar à análise que iniciava, surgiu-me o esboço de uma avaliação crítica sobre a mesma:

"Nossa análise neste trabalho parece 'economicista'; de fato, privilegiamos o aspecto econômico, porque concebemos o processo produtivo guardando determinações fundamentais no capitalismo, que não são tão evidentes e exigem um esfoço de desvendamento"'

Em seguida, justificava enquanto claramente política a discussão econômica de Cubatão, buscando no homem morador das favelas o trabalhador do centro produtivo em questão, mesmo que esta postura tivesse um caráter redutor como análise desse homem favelado e de seu dia a dia, que conscientemente sabia não recuperado, em toda sua amplitude. Mais ainda, havia um desvio da análise da favela para a do favelado, e deste como trabalhador. Embora, no capítulo final, a discussão da favela tenha sido retomada, ela não moveu todo o trabalho. Concluindo, essa forma urbana foi marginalmente avaliada.

Nos momentos finais da dissertação, a favela, os limites e as formas de apropriação dos serviços urbanos que a caracterizam, revelava a perda da cidade por parte desses núcleos e de seus moradores. Então, avaliei que essa perda da cidade não só resultava como se tornava condição de reprodução das relações sociais de produção, reportandome a Henri Lefebvre e Agnes Heller no desenvolvimento da temática.

Estava exposta uma inquietação que veio a perseguir os últimos anos de minha pesquisa e que se traduzia, no limite último, num tratamento do espaço não apenas como continente tardio de relações sociais, cuja lógica independesse dele. ${ }^{2}$

Minha tentativa de contribuição a essa discussão baseia-se menos na relação entre espaço e produção social, na qual aparece a teoria do valor como fundamental à concepção de espaço social; e mais na relação entre espaço e reprodução sociais. Em outros termos, espaço e formas de reprodução da formação econômico-social capitalista. Uma abordagem obviamente não exclui a outra. Do que se trata é do foco privilegiado de análise, do momento a partir do qual se recupera a globalidade social, já que produção e reprodução são momentos do processo produtivo no seu sentido mais amplo.

Influenciada por esse meu ponto de partida, de forma até ansiosa, como motor de meu raciocínio fugi de uma perspectiva econômica, comprometida com as relações de produção estritas no interior da fábrica (às quais me detive especialmente na dissertação de mestrado). Assim, o estabelecimento das relações entre o econômico, o político e o social se tornou mais complexo. Fiquei menos suscetível a considerar cada um desses níveis como reflexo um do outro, a partir da base econômica, e entrei no emaranhado do que poderia compor o social. O social não se autonomizou com uma instância em separado, mas, por outro lado, já não era tão facilmente desvendado a partir do econômico. Surge, então, uma hipótese, aquela de aguçar o sentido da observação e da pesquisa face ao que aparece como marginal e trivial dentro dos processos sociais, e que a complexidade do mundo atual, especialmente da vida urbana, recolocaria. Com isso, passo pelo fascínio da difícil relação entre a micro e a macro histórias e examino, confesso de forma passageira, a contribuição da Geografia Comportamental e da teoria fenomenológica sobre o espaço vivido. ${ }^{3}$ E concluo:

(1) Introdução de minha dissertação de mestrado, "Na busca das favelas o encontro do 'peão' que permanece”, apresentada, em 1984, Faculdade de Filosofia, Letras e Ciências Humanas, da Universidade de São Paulo.

(2) Muitos autores geógrafos insistiram, em mais de um trabalho, nessa leitura alternativa do espaço, como Milton Santos, Ana Fani Alessandri Carlos, Odette Carvalho de Lima Seabra, Antonio Carlos Robert de Morais e outros.

(3) Dentro da bibliografia de apoio constam: Johnston, R.J., Geografia e geógrafos, São Paulo, Difel, 1986; Bettanini, Tonino, Espaço e ciências humanas, Rio de Janeiro, Paz e Terra, 1982; Frémont, Armand, A região, espaço vivido, Coimbra, Almedina, 1980; Estébanez, José, Tendências y problemática actual de la Geografia, Madri, Cincel, 1982; 
- O apelo à psicologia, nos limites da Geografia Comportamental, ao behavorismo, com a variação de estímulos implicando a variação de comportamento dos indivíduos, pode ter validade apenas nos limites da compreensão dos interesses e do ponto de vista da concepção da publicidade, da propaganda, da manipulação do imaginário social, através das quais se amplia qualitativa e quantitativamente o consumo e os produtos consumíveis.

- Em princípio, o espaço da vida cotidiana parecia dar conta de uma ampliação de perspectiva a respeito do social, a que me propunha. Contudo, a problemática desse espaço cotidiano amarrada ao espaço vivido (assentado, por sua vez, na fenomenologia) coloca-me diante de novos impasses, difíceis de superar; especialmente, a questão e o lugar do social e do histórico nessa temática.

A questão da percepção do espaço sob esse ângulo acentuava o papel da experiência pessoal e o cunho antropológico de análise. Ambas considerações atraentes, mas particularmente pairavam dúvidas, como a da incorporação dinâmica e interna da concepção de sociedade e do social à análise. A relação entre o individual e o social é de intrincada resolução, e aparece como problema ${ }^{4}$. De outro lado, a relação entre a história humana como um todo, numa perspectiva antropológica, e a formação econômico-social capitalista em particular, como um momento dessa história, também apresentava uma solução complicada, inclusive em termos metodológicos. ${ }^{5}$

De qualquer forma, um tratamento de cunho fenomenológico remete à questão dos valores, do simbólico, resgatando o ponto de vista do habitante, sobre o qual, direta ou indiretamente, a pesquisa, em princípio, esboçava refletir. Inclusive, a problemática do espaço vivido acordou-me para as restrições de minha formação frente à psicologia, aos estudos de linguagem, aos seus fundamentos filosóficos, etc.

Não insisti nesse modo de reflexão, procurando um terreno mais conhecido e fértil. Considero um espaço aberto a posteriores pesquisas.

As primeiras aproximações teóricas a respeito do tema, assim se apresentavam.

O capitalismo não é um sistema ou uma totalidade fechados, cuja estrutura acabada, pronta, trata-se de des- vendar, e que somente se sensibilize com mudanças quantitativas. O que existe é um "esforço no sentido da sistematização - no sentido da coerência e da coesão".

O capitalismo configura, na verdade, um processo de desenvolvimento contraditório. Enquanto produção estrita de coisas, embora não se resuma a ela, tende a transformar e sujeitar a natureza inteira, os diferentes lugares, e mais e mais elementos e momentos da vida social à lógica da mercadoria, da troca.

O crescimento industrial, o desenvolvimento da técnica, entrevendo uma produtividade sem limites; a importância do ócio, o controle não só da demanda solvável, mas dos desejos e necessidades dos consumidores, por parte dos que organizam a produção (destaque à publicidade, à ideologia do consumo); os limites de uma racionalidade burocrática, organizando o consumo, assentada no cotidiano, são algumas das leituras desse processo, que criam designações, tais como: sociedade industrial, sociedade técnica, sociedade do ócio, sociedade de consumo, sociedade burocrática de consumo dirigido, nascidas ou difundidas, já no início da segunda metade do século XX.

Este processo, portanto, não se consubstancia apenas como uma massa cada vez maior de mercadorias produzidas e nem de um ponto de vista apenas numérico, quantitativo. Todo conjunto social, a globalidade social se alteram com essa incorporação. Ela é subvertida, atingida na sua totalidade e em cada um de seus elementos, ao nível de sua substância material e de suas significações. O esforço de reprodução da sociedade atinge outros níveis da prática social e os atinge de forma mais sútil. A valorização da ativi-

Maffesoli, Michel, L'espace de la socialité, in: Vários autores, Espaces et imaginaire, Grenoble, Presses Universitaires de Grenoble, 1979; Balandier, Georges, Essai d'identification du quotidien, Cahiers Internationaux de Sociologie, Presses Universitaires de France, 1983, volume LXXIV; Sansot, Pierre, Ville et Poésie, in: Revue Espaces et Socités, Paris, Anthropos, abril de 1975, n.15; Ladrière, Jean, Vida Social e Destinação, São Paulo, Convívio, 1979.

(4) O tema da particularidade, da individualidade e da universalidade no interior do desenvolvimento do gênero humano aparece constantemente na obra de Agnes Heller; destaco: Sociología de la vida cotidiana, Barcelona, Península, 1977.

(5) O problema da interpenetração entre as leis universais e as leis específicas, enquanto leis do devir no desenvolvimento da formação econômico-social é tratado por Henri Lefebvre, especialmente, em O Pensamento de Lenine, Lisboa, Moraes, 1975. 
dade criadora tende a desaparecer, o "racional" e o organizado tomam seu lugar. O espaço, o tempo, o urbano, o cotidiano são colonizados, atingidos, metamorfoseados. Consolidam-se a idéia de espaço homogêneo - sujeito a compra e venda -, fragmentado - funcionalizado - e hierarquizado; a concepção de tempo linear - o do relógio, o do trabalho abstrato, invadindo o vivido -; a concepção dos tempos cooptados - o tempo livre à televisão, à indústria do turismo, etc. -; as distâncias alongadas entre o trabalho e a moradia, consumindo o tempo restante, além de toda a burocracia aumentada nos pequenos fatos cotidianos, etc. Recriamse novos conflitos, novas contradições.

Assim, a produção estrita de coisas, ou o acento no crescimento econômico, ou a ideologia do crescimento ilimitado - quantitativo, medido em toneladas, em quantidades de produtos, em eficiência -, que vivemos, no mesmo momento em que se acentua, exige que a superemos, pois sua resolução transcende o nível estritamente econômico. Esta racionalidade quantitativa, produtivista, economicista, que no nível real e ideológico passa a dominar, atinge a complexidade das relações sociais, dos outros aspectos da realidade social: valores, conjunto de signos e significações, formas de vida. Está em jogo a simplificação, o enriquecimento ou o empobrecimento das relações sociais. Portanto, imbricada à noção de produção no sentido estrito, temos que lidar com a produção no sentido lato, amplo, equivalendo à produção do homem mesmo, a produção da natureza humana e à reprodução da natureza, realizando-se, ao mesmo tempo, que a produção de coisas. A produção da civilização humana. E exatamente o acirramento das relações de propriedade, o desenvolvimento da propriedade privada, o das relações de dominação neste processo, corroboradas por estratégias políticas cada vez mais sofisticadas, colocam em níveis extraordinários e multiplicados o volume das alienações, a que estão sujeitos os grupos e os indivíduos. Lefebvre insiste que, neste momento histórico, já não se trata mais da elucidação do capitalismo através da reprodução dos meios de produção e da reprodução da força de trabalho, mas da questão da reprodução das relações sociais de produção, à qual Marx aludiria no Capítulo Inédito. Isto é, faz-se um percurso da idéia de produção de bens materiais, de produtos, até a produção da natureza pelo homem, a produção do homem por si mesmo, e, no interior desta produção no sentido amplo, a idéia de reprodução das relações sociais. A sociedade, da forma como está constituída, não só se perpetua produzindo novos produtos, mas reproduzindo relações sociais determinadas, de subordinação e de dominação. ${ }^{6}$
"A reprodução das relações de produção implica tanto a extensão como a ampliação do modo de produção e da sua base material ... o capitalismo constitui novos setores de produção e por conseqüência de exploração e de dominação; citem-se entre outros os seguintes setores: tempos livres, vida cotidiana, conhecimento e arte, e, finalmente a urbanização."7

Da mesma forma, nas palavras de Andre Granou, pinçadas aqui de seu trabalho "Capitalismo e modo de vida" (profundamente mais completo e rico) está em jogo "a extensão da base social sobre a qual se reproduzem as relações de produção capitalistas", ou "o alargamento das mesmas a toda a sociedade, até ao modo de reprodução da vida"

Esta expansão do capitalismo caminha em direção a tornar relevante para sua análise outros momentos da vida social, que podem estar no centro dos problemas atuais, permitindo a leitura do movimento de seu desenvolvimento. Estaria em jogo, além dos ciclos e circuitos da produção econômica, processos mais complexos, onde o esquema conceitual que define a base econômica e a superestrutura reduzida a instituições e ideologia -, como reflexo da primeira, seria extremamente pobre.

Tempos e lugares que passivamente refletiam as relações de produção dominantes, ou preservavam outras relações tradicionais, se é possível no limite último pensar-se desse modo, cada vez mais devem ser observados, na leitura do processo de acumulação, no sentido cabal.

A ingenuidade desses tempos e lugares, sua inércia relativa vai se esboroando. Neles podem estar contidos pedaços fundamentais da explicação.

(6) “... não há nem pode haver simples reprodução alimentada pela ideologia e seu corolário, a repressão. Não há reprodução das relações sociais sem uma certa produção de relações: não há aqui um processo puramente repetitivo." (Lefebvre, Henri, A reprodução das relações de produção, Porto, Escorpião, 1973; 1a parte do livro La survie du capitalisme, onde aparece de forma concentrada o esforço de compreensão desse tema). Ainda do mesmo autor, o espaço estreitamente vinculado à reprodução das relaçōes (sociais) de produção, é especialmente desenvolvido in Espacio Y Política, Barcelona, Península, 1976.

(7) Lefebvre, Henri, O pensamento marxista e a cidade, Póvoa de Varzim, Ulisseia, 1972, pp.168-169.

(8) Granou, Andre, Capitalismo e modo de vida, Porto, Afrontamento, 1975. 
A perda da cidade reaparece como tema, mas não necessariamente atrelada à pobreza material, à pobreza absoluta, na figura da ausência de serviços e equipamentos urbanos. Aparece, em última instância, como perda de fluidez da vida urbana, como perda da vida urbana propriamente, e de suas possibilidades. A deterioração da vida urbana não seria fundamentalmente função do crescimento das cidades, identificado ao crescimento de problemas e carências materiais estritas.

Algo de qualitativo e novo está acontecendo, ao mesmo tempo, a exigir observação. Pois é perversa e continuamente novo. Naqueles espaços e tempos marginais as relações pré-existentes estão sendo metamorfoseadas. Mais ainda, as relaçōes de exploração no interior da fábrica são corroboradas, fora e dentro da fábrica, por relações de dominação. A sociedade, reproduzindo suas próprias condições, vicia-se transformando tempos e espaços, em princípio, marginais. Desse modo, vê-se potencializada a capacidade de permanência das relações sociais.

Do que se trata é também deslocar, de certa forma, o centro "onde se produzem e reproduzem as relações globais".

Durante um tempo, em função da polêmica de Engels com Proudhon, retratada em "Para a questão da habitação", pareceu-me que jescentralizar a temática das relações de produção predominantes - as de exploração direta do trabalhador - tendia à deformação dos verdadeiros problemas sociais. Nesse momento, a cidade como tema chegou a parecer um desvio face a esses verdadeiros problemas, do ponto de vista da transformação da sociedade. A cidade restringida à reprodução da força de trabalho remetia à tônica da exploração direta do trabalho.

Uma nova perspectiva seria apenas moda a nos mover o raciocínio inconsciente, como uma onda internacional que nos atinge e cega?

$\mathrm{O}$ tratamento das cidades se complica, ainda mais, considerando a realidade urbana de países como o nosso, que assusta pela grandeza de algumas de suas cidades, exigindo explicações não convencionais, complicadores, à relação direta entre processo industrial e urbanização. ${ }^{10}$

Apesar do crescimento das cidades, a cidade como tal, não seria um atalho, mais ainda, um esconderijo, dos verdadeiros problemas sociais, que a sociedade coloca?
Essa inversão absoluta, face à convicção inicial de uma mudança necessária de perspectiva, tem uma raiz: no tema do cotidiano, que guarda a trivialidade aparente do social, é fácil perder-se a idéia de totalidade social, confundindo-se o cotidiano com o banal. Acreditando-se que iluminar a banalidade de forma espetacular já baste. No máximo, a utilização do "histórico" como o vagar por diferentes épocas à cata de similitudes e divergências furtivas e sugestivas. Sem projeto, o cotidiano representaria a ausência de compromisso com as grandes estruturas, o fascínio dessa ausência, num mundo em que o pensamento devotado a elas se mundializou e, ao mesmo tempo, esvaziou-se.

Contrapondo-se a essa expectativa, acredito que é preciso localizar historicamente o cotidiano como tema, definir quando ele passa a contribuir para o desvendamento do social.

O cotidiano inclui o homem inteiro em seus diferentes momentos: o da vida privada, o dos lazeres, o do trabalho; e exatamente quando cada um desses momentos se constitui como tal, sustentado por instituições, organizações, poderes, conhecimentos, é que o tema se torna crucial.

Quando cada momento se realiza como tal, e vive se repartindo ainda mais, é que o cotidiano aparece como totalidade. Totalidade costurada, arquitetada no seio da desintegração desse homem inteiro, homem cada vez mais cindido, dividido. A lógica, o pensamento analítico se realiza socialmente; cada momento da vida social tenta se estabelecer como realidade autônoma. Tenta criar um mundo.

Mais que isso, um momento compensa vazios dos outros momentos. Um vem colmar o outro. E todos são invadidos por cadeias de instituições e poderes, não dominados.

Para Philippe Ariès, o vazio de vida urbana é preenchido pela hipertrofia da vida familiar, cuja crise se projeta e se explica, portanto, através do urbano esvaziado. ${ }^{11}$

(9) Engels, F., Para a questão da habitação, Lisboa, Avante, 1984.

(10) Veja a respeito dessa singularidade: Castells, Manuel, Problemas de investigação em sociologia urbana, Lisboa, Presença, 1975; Santos, Milton, O espaço dividido: os dois circuitos da economia urbana dos países subdesenvolvidos, Rio de Janeiro, Francisco Alves, 1979; e outros.

(11) Ariès, Philippe, A família e a cidade. In: Figueira, S.A. e Velho, G. (orgs.), Família, psicologia e sociedade, Rio de Janeiro, Campus, 1981. 
Henri Lefebvre, que me serve, especialmente, de guia, mas a quem não posso responsabilizar por essas notas, dada a complexidade de sua teoria e suas transformações ao longo do tempo, frente às mudanças da própria realidade que pretendia ler ${ }^{12}$, e minha expectativa de uma busca particular e modesta, que me faz (re)ler, num de seus escritos, o primeiro deles sobre o tema, ao tratar da vida cotidiana, desenvolve a idéia da ruptura entre o domínio da natureza e sua apropriação pelo homem. A partir daí, inclusive, é possível pensar no desnível, nas fissuras entre as conquistas humanas - a técnica e a ciência avançadas - e o subdesenvolvimento do cotidiano, relegado aos resquícios desses avanços. E mais, essa falta de controle do que o homem, em princípio, domina, pois a vida cotidiana é particularmente o lugar do homem expropriado, sugere a inserção de meios de integração desse homem alheios à sua consciência, para fora de sua vontade. Neste sentido, fala da extensão do controle estatal, e do Estado, repousando sobre o cotidiano. A inscrição das técnicas, do saber no cotidiano, vindos do alto, reproduz a distância entre o poder e o homem comum. Ainda estamos diante da contradição maior entre o desenvolvimento das forças produtivas e as relações de produção (relações de exploração e dominação).

Essa totalidade que é o cotidiano, e que se realiza como espaço e tempo onde os pedaços se integram "pelo alto", reviveria, estenderia, revitalizaria a própria ordem industrial.

Com o desenvolvimento do capitalismo é preciso reconhecer, como já mencionado, que não está aprisionado somente o tempo de trabalho - trabalho que se perde como trabalho qualitativo e realização do ser humano, através de sua atividade -; o tempo de não-trabalho sofre mais e mais interferências, da organização da indústria e das estratégias políticas. A rigor, em Marx, já aparecia que, a compreensão, de forma cabal, da lei da acumulação capitalista, exigia transcender o processo direto de produção e de exploração direta da força de trabalho, preocupando-se, naquele momento, com o levantamento das condições de habitação dos trabalhadores. ${ }^{13}$

Essa separação-integração tende a se projetar francamente no terreno. Um tratamento analítico da vida social preenche o espaço. E é necessário medir até onde desdramatiza a própria vida. São os espaços funcionais, já apontados.

Um certo saber, assegurado por forças políticas, realiza-se socialmente, praticando esse fracionamento. Tratase do urbanismo moderno.
Os conjuntos habitacionais aparecem como uma de suas versões mais vulgarizadas. Neles, especialmente, o cotidiano programado parece encontrar sua forma mais adequada. Catalogando e discernindo necessidades e as isolando no terreno. Tudo é concebido separado, projetado isoladamente, sobre "ilhotas" desunidas: as áreas de serviços e comércio, as de lazer e de habitação.

Retratariam uma cidade, um bairro, que perderam sua sociabilidade viva, como "autênticas maravilhas de monotonia e regimentalização", como espectro da cidade, fantasma de uma urbanidade orgânica? Essa funcionalidade extrema, que os caracteriza, faz com que se perca a imediaticidade, com relação ao espaço? Reduz os vários significados que pode ter um mesmo lugar, ratificando sua própria funcionalidade?

Então, eles podem representar o espaço de outra forma de pobreza, de novas alienações, como a pobreza de vida urbana.

O espaço dos conjuntos habitacionais, como face da deterioração do urbano passou à foco de interesse.

Que mundo é esse que impõe a lógica formal como prática? Segundo Michel Foucault em "Vigiar e Punir", não é tão novo; data da expansão da razão clássica, desde o século XVII, que, com a disciplina, fabrica corpos submissos e dóceis, a partir, inclusive, de espaços constituídos como minúsculos observatórios sociais ${ }^{14}$. E Lefebvre o emenda: "ele não distingue a presença do Estado na cena, ao lado da razão"15. Sem buscar essa gênese, é possível dizer-se

(12) O movimento do conhecimento de Henri Lefebvre sobre o cotidiano se expressa nos seguintes livros: Critique de la vie quotidienne I, Introduction, Paris, L'Arche éditeur, 1977 (escrito originalmente em 1946); Critique de la vie quotidienne II, Fondements d'une sociologie de quotidienneté, Paris, L'Arche éditeur, 1980 (escrito em 1961); La vida cotidiana en el mundo moderno, Madri, Alianza Editorial, 1984 (escrito em 1968); e, Critique de la vie quotidienne III, De la modernité au modernisme (pour une métaphilosophie du quotidien), Paris, L'Arche éditeur, 1981 (escrito neste ano). Acrescente-se a esse conjunto, de forma mais marginal, Posição: contra os tecnocratas, São Paulo, Documentos, 1969.

(13) Marx, Karl, El Capital, Argentina, Siglo Veintiuno, 1975, Tomo I, volume 3. 1975.

(14) Foucault, Michel, Surveiller et punir, Paris, Gallimard,

(15) Lefebvre, Henri, De L'état - 1, L'état dans le monde moderne, Union Générale d'Éditions, 1976, p.162. 
que essa razão realizada é, também, a do mundo que cresce enquanto mundo; onde, especialmente, crescem as cidades; onde o crescimento demográfico ainda assusta, e o malthusianismo se preserva e se torna justificativa.

A leitura ideológica que está por traz de projetos como os dos conjuntos habitacionais, ou a sua justificativa, que tem um aspecto real, diante do tamanho das cidades, no corpo da sujeição às relações capitalistas de produção e à apropriação privada da terra e da habitação, é a da demografia galopante, a da necessidade de reprodução biológica, a da sobrevivência, face à quantidade dos déficits habitacionais ou ao montante das habitações necessárias; preterindo o estudo das relações sociais concretas, ou mascarando o plano da reprodução das relações sociais. Os problemas que surgirem neste nível terão também uma resposta institucional. Em nosso país, os grandes conjuntos habitacionais aparecem, entre outras, como solução habitacional barata, relativamente, e necessária para determinada faixa da população que, de outra forma, concentrar-se-ia em favelas e cortiços. ${ }^{16}$

Aqui chegamos a um ponto fundamental. O cotidiano não é somente ordem imposta, ele é, no plano subjetivo, uma organização de vida assegurada. Quando o banal do dia a dia, como se alimentar, vestir-se, alojar-se, locomoverse, produzir, faz parte da vida de forma segura. Com esses tempos, atividades e espaços conquistados de maneira que parece definitiva. É a ordem diária da segurança material. Tendo cotidiano se dorme em paz. Lefebvre define o cotidiano, neste sentido, como algo entre o infra-cotidiano e o supra-cotidiano, enquanto uma sorte de média social. No primeiro volume da "Crítica da vida cotidiana", ele adverte: "por todos os lugares, homens e mulheres aspiram a estabelecer solidamente sua vida cotidiana, a escapar da insegurança, como da miséria"(p.60).

Países como o nosso, onde sobrevivem problemas de carências elementares, significaria que milhões de pessoas estão vivendo o infra-cotidiano. Aqueles que vivem nas favelas e cortiços, convivendo com a possibilidade iminente da perda da casa, têm na casa própria a ascensão ao cotidiano.

A estrutura rígida, que grandes conjuntos habitacionais pode significar, fica desapercebida ou é deixada para um segundo plano, quando consciente. A funcionalidade extrema desenhada no terreno não é vivenciada como tal, mas enquanto necessidades básicas satisfeitas.
Simultaneamente, implodem-se grandes conjuntos habitacionais na Europa e nos Estados Unidos, quando aqui eles são construídos.

No limite último, no nosso caso, o conjunto habitacional pode representar a instalação no cotidiano? Nem sempre. Há casos em que apesar da estrutura urbana implantada, da casa própria assegurada, o cotidiano, para milhares de pessoas, não foi atingido. Cidade Tiradentes, um grande conjunto em Guaianazes, São Paulo, pode nos fornecer o exemplo. A interpretação é um desafio, que remete à própria relação entre forma e conteúdo.

Com conteúdos mais estéreis, por princípio, essa forma urbana delimita a vida humana. Mas as coações, que ela implica, são enfrentadas ao nível da prática urbana, que, por sua vez, recupera as múltiplas relações entre o homem e o espaço, expondo ambos à história, às estruturas e conjunturas, à cultura adquirida, às inserções sociais, até ao imaginário e imaginação sociais, aos desníveis e fissuras entre as macro estruturas e o espaço vivido cotidianamente, que, então, caracterizam possibilidades de apropriação, também, múltiplas.

É o nível das relações dialéticas entre coações e apropriações, que, inclusive, permite a inserção de imprevistos, resíduos, acasos, que a magia das possibilidades históricas torna real.

Mas sobra, como fato e problema, a força social e política que a rigidez dessa forma implica, porque, na expressão de Walter Benjamin, "são espaços nos quais é difícil deixar rastros"17. Abruptamente se instalam e tendem a arrastar as referências anteriores. A (re)construção é dolorosa.

A questão em nosso país fica complexa face ao primado das necessidades básicas, como já dito. A força reprodutora dessa forma por isso se amplificaria?

(16) "O urbanista obedece passivamente às pressões do número e do menor custo; a funcionalidade que ele crê conceber se reduz à ausência de funçōes 'reais', à função do puro olhar." (Lefebvre, Henri, La révolution urbaine, Paris, Gallimard, 1970, p.41).

(17) Benjamin, Walter, Documentos de cultura, documentos de barbárie - escritos escolhidos, São Paulo, Cultrix - Editora da Universidade de São Paulo, 1986. 
De qualquer modo, uma coisa é a concepção de espaço do arquiteto; outra pode ser a realmente vivida. Em última análise, poder-se-ia dizer que esse morador - com certo desenho urbano presente, segundo seus valores e modo de ser - com o tempo, ou num certo momento, vive o espaço projetado, nos termos do arquiteto. Poderá nunca fazê-lo, ou fazê-lo em conjunturas específicas; ou, ainda, em último caso, fazer coincidir sempre espaço do arquiteto e espaço do morador. Pode haver, e é o que observo, mais de uma interpretação, de um modo de viver um conjunto habitacional, que equivale a essas formas de interpretação e representação do espaço projetado. Neste sentido, o modo de viver desses moradores pode realizar ou não, da forma prevista, o espaço projetado pelo arquiteto. Uns moradores já vivem seu rigor, outros não. A adequação entre forma e conteúdo é complicada.

Mas é possível se falar na neutralização absoluta desse espaço, assim organizado?

"Se a própria forma já traça a sua atividade, se promete um certo futuro, este futuro não é uma predestinação absoluta ou, se o é, ocorre uma revolta", escreve Henri Focillon. ${ }^{18}$

Mesmo quando a cotidianidade organizada, proposta nessa forma urbana, não atinge plenamente os moradores dos conjuntos, em especial no nosso caso, a hipótese de que esse espaço planejado integraria, de um modo particular, o homem urbano ao país, à nação, ao Estado, o devolveria às atividades produtivas com uma certa configuração; o que não foge à proposta "ideal", mas, ao contrário, realizaria, de alguma forma, o constrangimento, que adere a essa forma, como significação. Trata-se da integração "pelo alto".

Embora pobre, definido por linhas muito elementares, o espaço dos conjuntos habitacionais é um eco do movimento moderno em arquitetura. Os arquitetos, contactados, envolvidos em sua concepção, afirmam sua inspiração "modesta" em Brasília.

A repetição, a idéia da quadra, a funcionalidade dos espaços, a massificação da produção norteiam a produção desses conjuntos. Estamos, ao lidar com os conjuntos habitacionais, refletindo sobre os limites do processo de vulgarização das concepções desse movimento. Historicamente, se ele ganha plena configuração nas primeiras décadas do século XX, esse processo de vulgarização data, especial- mente, da segunda metade deste século. É um produto, na Europa, da segunda guerra mundial, da destruição das cidades, somada à expansão urbana. Ele se mundializa a partir de mais de um centro de influência. Conversando com um arquiteto brasileiro, a respeito de nossa experiência em conjuntos habitacionais, ele foi incisivo: "nossa experiência está mais próxima da experiência russa, do que da francesa". Até como metáfora, ele queria acentuar que a experiência brasileira era muito elementar. Na verdade, a arquitetura e o urbanismo modernos chegam a nós tanto na sua configuração mais elaborada, a exemplo de Brasília, quanto na sua feição mais rudimentar, através dos conjuntos habitacionais, especialmente, da realização de grandes conjuntos habitacionais. Digo especialmente, porque, através dos grandes conjuntos habitacionais, a experiência arquitetônica e urbanística proposta é vivida de forma mais pura, menos acoplada e misturada a outros momentos e espaços da cidade. O resultado dessa representação específica do espaço, através dos grandes conjuntos, é mais nítido. É sofrido e vivido de forma mais límpida, em sua crueza, menos sujeito a outras influências concomitantes. Tanto assim se dá que, em mais de um momento, foram sugeridas políticas de inserção dos grandes conjuntos, na malha urbana, tendo em vista a realidade mais isolada que representam.

A idéia não é fazer uma crítica à arquitetura moderna, através dos conjuntos; pois, não caberia. Eles, especialmente no país, não a expressam, convenientemente. Mas, ao mesmo tempo, trata-se de demonstrar o limite e os compromissos de um pensamento, deste pensamento-ação. À rigor, a representação do espaço, que norteia a arquitetura moderna aparece, aqui, como caricatura. Portanto, hipertrofia certos aspectos seus e com eles o umbral do significado a que pode chegar. A mundialização de um pensamento, que sofre desdobramentos e distorções, exige, necessariamente, ao ser lida, considerar o embate com realidades sociais distintas, que trava em países diferentes e conjunturas diferentes. Não há somente o movimento de uma idéia, mas o movimento de idéias, que se realizam em condições sociais diversas. Imbricados o real e o pensamento. E, assim, desembocamos nas condições de realização, de um trabalho como esse, no nosso país. As comparações com outras experiências, de outros países, exigiria esforços redobrados. É notório, no entanto, que a experiência de grandes conjun-

(18) Focillon, Henri, Vida das formas, Rio de Janeiro, Zahar, 1983, p.80. 
tos, em muitos países, foi abolida. Foi comum usarem-se as implosões. Enquanto na França, em 1973, surge uma legislação impeditiva à construção de grandes conjuntos ${ }^{19}$, aqui no Brasil, à década de 70, essa experiência proliferou. E ela chegou a conjuntos de tamanhos descomunais, verdadeiras "cidades", de mais de 20000 unidades.

Ainda merece consideração a importância do espaço da cidade como espaço diferencial.

O espaço da cidade, de um lado, caminha para a constituição da forma-conjunto, enquanto uma história de produção, em São Paulo, de uma cidade segregada, segmentada. Bonduki fala da importância dos anos 20 aos 40 deste século, na consolidação da periferia e no esvaziamento do centro de São Paulo, dados os termos de desenvolvimento da industrialização, as políticas urbanas, como o Plano Avenidas, nos anos 30, baseado numa proposta de reformulação da estrutura viária, etc. ${ }^{20}$ Por outro lado, o espaço tem essa propriedade complexa de guardar tempos históricos, e os fixar - a questão das sobrevivências, tratada por muitos geógrafos, como Milton Santos com as rugosidades do espaço ${ }^{21}$-, constituindo um impedimento ao movimento, imobilizando e impondo conteúdos; ao mesmo tempo, nesses tempos resguardados, aparece a memória da vida da cidade. Para seu habitante, metamorfoseada à sua experiência pessoal e social, faz reviver conteúdos avessos, muitas vezes, às formas atuais e impostas. O habitante dos conjuntos também vive o restante da cidade, e, como memória, outros modos de vida já vividos em outros lugares. Outros cantos da cidade, de onde vieram.

O espaço da cidade aparece como um nível intermediário importante ao processo de explicação. Se o nível global se impõe - as políticas, o Estado, a empresa, as organizações e instituições -, esse espaço não os recebe passivamente $^{22}$. Se há uma maior proximidade entre as intenções e imposições do plano global, transposto ao terreno, e sua realização na cidade, através da forma-conjunto, já que é um espaço deshistoricizado e funcional, este encontra na própria cidade uma contradição.

Então, o conjunto seria a expressão da deterioração da cidade, como urbanidade viva, demonstrando limpidamente a racionalidade técnica e burocrática - como forma espacial do cotidiano organizado -, que já vem se impondo à e na cidade. $\mathrm{O}$ urbanismo institucional generaliza e sedimenta essa experiência de segregação. Mas, por outro lado, o espaço da cidade, de tempos complexos, tem como possi- bilidade (re)produzir essa forma-conjunto, redefiní-la e afrontá-la.

De qualquer forma, e apesar dos tantos conteúdos possíveis, porque não está absolutamente isolado da cidade e das outras experiências pessoais e sociais, o espaço preenchido pela forma-conjunto, sujeito ao que ela representa, não estaria sob pressão à redução dos diferentes conteúdos? A forma-conjunto não se imporia esteticamente na cidade, $\mathrm{e}$ assim, e inclusive, eticamente, constituindo-se num modo de vida, igualizando seus moradores no que diferem? A forma - conjunto, então, reproduziria socialmente seus moradores, recompondo sua inserção social? Acrescente-se, o que já foi abordado, sobre a integração "pelo alto", como risco desse tipo de "habitat".

O diretor Robert Carpenter, no filme "Alguém me vigia", trabalha o moderno em Los Angeles. A câmera pas-

(19) "Apesar de todas as críticas, os Grandes Conjuntos se multiplicaram sobre a paisagem de Paris durante vinte anos. Eram a resposta do Estado às demandas de habitação. Inundavam o horizonte submergindo as imagens românticas de Paris, e forjando uma nova e dura geração de moradores metropolitanos. Logo, um dia da primavera de 1973, desapareceram de repente como os dinossauros ... Desde a primavera de 1973 em diante, não se construiu um só Grande Conjunto, nem outros substituíram aos que se deterioravam. O conceito desapareceu. E, como os dinossauros, tratou-se de uma extinção repentina que, à primeira vista, segue sendo um mistério. Sem dúvida, os historiadores franceses, enroupados em seu cartesianismo, terão uma explicação definitiva: a "Circular Guichard" de abril de 1973. Como de costume, considerara-se que a história francesa foi mudada por decreto, de acordo com uma iniciativa do governo. É certo que a decisão do Senhor Guichard, ministro das obras públicas, de proibir a construção de qualquer conjunto residencial de mais de 2000 habitaçōes, sentenciou a morte da fórmula urbana que havia caracterizado os subúrbios metropolitanos franceses durante muitos anos." (Castells, Manuel, La ciudad y las masas: sociología de los movimientos sociais urbanos, Madri, Alianza, 1986, pp.121/122).

(20) Valladares, Lícia do Prado (org.), Repensando a habitação no Brasil, Rio de Janeiro, Zahar, 1981, pp. 135 a 168.

(21) Santos, Milton, Por uma nova geografia: da crítica da geografia à geografia crítica, São Paulo, Hucitec/Ed. da Universidade de São Paulo, 1978.

(22) "A política do espaço não conhece este senão como meio homogêneo e vazio, no qual se aloja objetos, pessoas, máquinas, locais industriais, fluxos e redes. Uma tal representação se baseia sobre uma logística de uma racionalidade limitada e motiva uma estratégia que destrói reduzindo-os os espaços diferenciais do urbano e do 'habitar'." (Lefebvre, Henri, La révolution urbaine, Paris, Gallimard, 1970, p.68). 
seia sugerindo ângulos retos, perspectivas e distanciamento, no tratamento dos edifícios condominiais, que somam mais de 2000 pessoas, cada um. Enormes edifícios enfileirados e prostrados uns frentes aos outros. Cada um perigosamente convive com o outro. As fachadas de vidro expõem a todos. A paisagem estimula o olhar estranho, que pode ser perigoso; em que um vigia o outro e não exatamente convive. De certa forma, pode-se perder o espaço interno da casa. Cada um representa um perigo para o outro, um intruso; e mais, todos contém o perigoso, pois retém a figura da vigilância, de forma interna. O que aparece como vigiar a partir do olhar do outro, potencializa-se na imagem interna que vigia a todos, controlando os edifícios: são os monitores dos prédios. O monitor representa o olhar, único e ameaçador. Ingenuamente técnico, detém o poder.

Em outubro de 1985, o jornal Voz da Comunidade, órgão informativo da Comunidade Católica da Cohab Itaquera I, conjunto que começou a ser entregue em 1978, escrevia em seu editorial: "a verdade é que só agora é que estamos sentindo o peso da estrutura e da forma de construção dos conjuntos da Cohab, planejados e construídos para isolar as pessoas umas das outras, controlar e manipular politicamente. E é aí que nosso trabalho missionário se torna um desafio." O mesmo número relata os resultados do "Encontro dos Agentes de Pastoral das Cohabs", entre os quais consta: "tomar providências para não deixar que se construa mais desses tipos de conjuntos."

Num livro belíssimo, intitulado "Morte e vida das grandes cidades", Jane Jacobs constrói o que ela convenciona como um ataque contra as teorias mais usuais sobre urbanização e reconstrução de cidades, que a scu ver não observam a densa rede de interconexões, que se forma nas cidades, necessitadas que são de uma intrincada diversidade de usos. Diversidade de uma cidade, que equivale a não inibir idéias e oportunidades não oficiais, em vizinhanças ativas e ruas apropriadas, de tal forma que não reproduzam o estranhamento..$^{23}$

A partir da redução dos princípios de planificação, que já reconhece na cidade jardim, de 1898, de Ebenezer Howard, ela desenvolve uma questão, à qual este trabalho deve se deter, que é a do "populacho etiquetado". Cada população uma etiqueta com seu preço correspondente. "Pessoas marcadas como os signos hexagonais dos urbanistas, sacudidas, expropriadas e desenraizadas como se sobre elas houvesse abatido uma potência conquistadora" (p.8).

O espaço da vida cotidiana, mesmo num país como o nosso, amplia a noção da pobreza urbana, para além dos bolsões de pobreza absoluta, mesmo o considerando como uma utopia de massas enormes de empobrecidos moradores de favelas, cortiços, cantos de rua, indigentes, que aspiram uma vida organizada e uma casa segura. Um exemplo crucial é o da consolidação de um projeto de sociedade, pelo Estado, através do urbano. A redução das necessidades sociais e urbanas às mais elementares; uma leitura funcional dos desejos humanos, produzindo um espaço rigoroso, segmentado e massificante, faz dos conjuntos-cidades laboratórios do processo de deterioração do urbano, como fenômeno pesado de conseqüências na reprodução da sociedade brasileira. Não somente como forma de vida urbana, mas delimitando as aspirações sociais.

\section{RESUMÉ}

La réflexion sur le quotidien nous remettrait à "une sorte de moyenne sociale" et par conséquence à la détection de l'infraquotidien. En fonction de cela la critique de la vie quotidienne serait-elle ébranlée, dans un pays comme le Brésil, là où des millions de chômeurs, sans abri (SDF) survivent à peine et n'ont pas leur quotidien assuré, n'accèdent pas à la quotidienneté?

Ce cas est un cas limite; au dessus de cette limite, dans des conditions d'habitation et de travail relativement stables, qui concernent certaines couches sociales, cette critique est-elle valable ou bien la réalité brésilienne ébranlerait l'importance du quotidien comme construction universelle d'une pensée critique à propos du XXème siècle?
Selon Henri Lefebvre "tout projet d'urbanisme recèle un programme de vie quotidienne": les grands ensembles révèlent un quotidien programmé. Dans ce sens, aujourd'hui la production des grands ensembles au Brésil est tout à fait different du cas français. C'est l'objet de cette analyse. Déjà la dictature militaire brésilienne avait beaucoup investi dans ce paysage aride et froid des ces grands ensembles, depuis les années soixante-dix.

(23) Jacobs, Jane, Muerte y vida de las grandes ciudades, Madri, Península, 1973. Marshall Berman, em Tudo que é sólido desmancha no ar (São Paulo, Companhia das Letras, 1986), ao apreciar sua obra, define-a como expressão do modernismo da rua nos anos 60. 
Pourtant, les limites sont: celles de l'établissement dans le quotidien, celles du quotidien assuré, celles de la critique à peine insinuée.
Dans un pays comme le Brésil la critique de la vie quotidienne s'établit dans un niveau de dépassement à peine ébauché. 